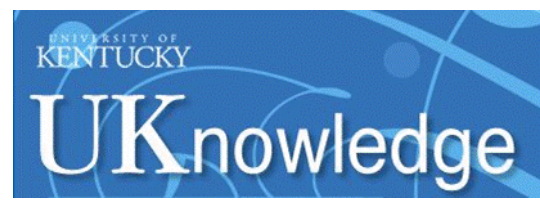

University of Kentucky

UKnowledge

$11-2015$

\title{
Evaluation of an Innovative Leadership Training Program for Chinese Students: Subjective Outcome Evaluation
}

Daniel T. L. Shek

University of Kentucky

Xiang Li

University of Kentucky

Follow this and additional works at: https://uknowledge.uky.edu/pediatrics_facpub

Part of the Pediatrics Commons

Right click to open a feedback form in a new tab to let us know how this document benefits you.

\section{Repository Citation}

Shek, Daniel T. L. and Li, Xiang, "Evaluation of an Innovative Leadership Training Program for Chinese Students: Subjective Outcome Evaluation" (2015). Pediatrics Faculty Publications. 195.

https://uknowledge.uky.edu/pediatrics_facpub/195

This Article is brought to you for free and open access by the Pediatrics at UKnowledge. It has been accepted for inclusion in Pediatrics Faculty Publications by an authorized administrator of UKnowledge. For more information, please contact UKnowledge@lsv.uky.edu. 


\section{Evaluation of an Innovative Leadership Training Program for Chinese Students: Subjective Outcome Evaluation}

\section{Digital Object Identifier (DOI)}

https://doi.org/10.1515/ijdhd-2015-0461

\section{Notes/Citation Information}

Published in International Journal on Disability and Human Development, v. 14, no. 4, p. 393-400.

(c) 2015 Walter de Gruyter GmbH, Berlin/Boston

The copyright holders have granted the permission for posting the article here. 
Daniel T.L. Shek* and Xiang Li

\section{Evaluation of an innovative leadership training program for Chinese students: subjective outcome evaluation}

DOI 10.1515/ijdhd-2015-0461

Received July 20, 2014; accepted September 3, 2014; previously published online September 17, 2015

\begin{abstract}
As a part of the Global Youth Leadership Program (GYLP), a 30-h "Service Leadership" subject was provided to 48 undergraduate students studying at The Hong Kong Polytechnic University (PolyU) or Peking University (PKU). This study evaluated the subjective outcomes of the "Service Leadership" subject, including students' views on the course contents, lecturers, and perceived benefits from the course. A majority of students in the program showed very positive perceptions of the course content, lecturers, and course benefits, with more than $85 \%$ of the students indicating that they were very satisfied with this subject and would suggest their friends to take the subject. As expected, the three domains of program effectiveness were significantly correlated amongst themselves, and these domains had different impacts on student overall satisfaction with the course as well as on student willingness to recommend this course to others and participate in similar courses again in the future.
\end{abstract}

Keywords: industrialization; manufacturing economy; post-industrialization; service economy; service leadership; service leadership model.

\footnotetext{
*Corresponding author: Daniel T.L. Shek, PhD, FHKPS, SBS, JP, Associate Vice President and Chair Professor, Faculty of Health and Social Sciences, Department of Applied Social Sciences, The Hong Kong Polytechnic University, Hunghom, Hong Kong, P.R. China, E-mail: daniel.shek@polyu.edu.hk; Centre for Innovative Programmes for Adolescents and Families, The Hong Kong Polytechnic University, Hong Kong, P.R. China; Department of Social Work, East China Normal University, Shanghai, P.R. China; Kiang Wu Nursing College of Macau, Macau, P.R. China; and Hong Kong Institute of Service Leadership and Management, Hong Kong, P.R. China

Xiang Li: Division of Adolescent Medicine, Kentucky Children's Hospital, University of Kentucky, Lexington, KY, USA; and Psychological Studies Academic Group, National Institute of Education, Nanyang Technological University, Singapore
}

\section{Introduction}

As the global economy transitions from a manufacturing economy to a service economy during the past decades [1], Hong Kong has become one of the most service-oriented economies in the world. The service sectors accounted for 93.1\% of Hong Kong's Gross Domestic Product (GDP) in 2011, and $88.4 \%$ of all employees engaged in different service sectors in 2012, including import/export, wholesale and retail trades, social and personal services, and public administration [2]. Although the proportion of the service industry to GDP in Mainland China is less than that of Hong Kong, the contribution of the service industry increased very quickly since the economic reform and opening up in 1979. Compared to $22.4 \%$ in $1983,33.7 \%$ in 1993 , and $41.2 \%$ in 2003 , the service industry contributed to 46.1\% of GDP in Mainland China in 2013 [3]. More remarkably, the added value of the service industry as a proportion of GDP has surpassed that of the manufacturing industry for the first time [4]. Such an irreversible trend greatly influences the economic structure of Mainland China, which is the second largest economic entity in the world [5]. Beyond a doubt, the service sectors have been regarded as the foundation of both Hong Kong and Mainland Chinese economies, and the service industry is of prominent importance to the national power of China. In contrast to the traditional manufacturing economy that emphasizes tangible products and standardized production process [1], a service economy requires high quality of service and flexible as well as creative ways of production.

In response to the growing trend of the service economy which contributes to a prosperous and vibrant China, service leadership as a new type of leadership model was proposed to re-define effective leadership in the industrial era and to meet the demands of the economic transformation from an industrial to a postindustrial economy. Effective service leaders are beneficial to improving service quality and promoting the competitive advantages of enterprises in the service economy era [6], who are expected to demonstrate qualities like intrapersonal and interpersonal intelligence, leadership skills, 
service competence, and systems thinking [7, 8]. Given that young people play such an integral role in the service industry, strengthening youth leadership, and nurturing more young leaders to serve oneself, other people and the whole society are top priorities in the current market environment [9]. In particular, university students who are expected to become effective service leaders should enhance their leadership competencies to promote positive social development, both locally and globally.

As universities have the obligation to cultivate youth leadership, a series of service leadership initiatives including credit bearing subjects and non-credit bearing programs have been offered to nurture high quality university students at The Hong Kong Polytechnic University (PolyU) [8]. Since the 2012-13 academic year, a 2-credit elective General Education subject "Service Leadership" was offered to undergraduate students. This piloted subject was based on the positive youth development approach and service leadership framework that was developed by the Hong Kong Institute of Service Leadership and Management (HKI-SLAM), with a basic postulation that Effective service leadership consists of Moral character, Competence and Caring dispositions $\left(\mathrm{E}=\mathrm{MC}^{2} ;[10]\right)$. To better promote student service leadership through developing the character strengths, intrapersonal and interpersonal competencies, and caring dispositions, the subject adopted innovative teaching strategies, including lectures, experiential learning, group presentations, and written assignments. As expected, evaluation findings of "Service Leadership" subject showed that most students who took the course showed high levels of overall satisfaction with the course with very positive perceptions on the course contents, lecturers, and course benefits [11, 12]. Additionally, over $50 \%$ of the participating students had the willingness to recommend the course to their friends and take similar courses again in the future [12].

Leadership training programs are commonly used to promote leadership qualities in university students. However, most existing programs mainly focus on leadership skills, while little attention has been placed on nurturing youth moral character and caring dispositions [13]. Against this background, besides the credit bearing "Service Leadership" subject developed for nurturing student service leadership, two non-credit bearing programs including "Wofoo Leaders' Network Workshops" (WLN) and "Global Youth Leadership Program" (GYLP) were designed at PolyU. While WLN workshops were offered to students from all tertiary institutions in Hong Kong which consisted of three series of service leadership training workshops, GYLP was a 2-year leadership learning initiative with various cross-territorial activities jointly administered by PolyU and Peking University (PKU).

The GYLP was designed to help students develop in a holistic manner, with the intent to promote youth intrapersonal and interpersonal skills, to foster their sense of social responsibility and to broaden their international perspective. The program has five prominent features including holistic development; process-orientation; interactive and collegial learning environment; intercommunity and inter-disciplinary learning and development; and a "think globally, act locally" mindset. With multiple components (e.g. workshops, classroom learning, and study tours in different countries), this program covers a wide array of activities in Hong Kong, Mainland China, Cambodia, and the US.

Before visits to key government ministries, migrant and rural communities, and dialogue with business and community leaders in Beijing, a modified 4.5-day (30 h) "Service Leadership" subject as the theoretical part of the GYLP was prepared for all 48 participants at PKU with the aim of systematically enhancing student knowledge on service leadership and promoting student moral character, intrapersonal and interpersonal abilities, and caring dispositions. As scheduled, the original thirteen lectures of the "Service Leadership" subject were condensed into nine lectures, covering a wide range of topics related to service leadership. It should be noted that intensive course design would not lessen student academic outcomes and it would generate superior learning effect $[14,15]$. Moreover, the "Service Leadership" subject in the GYLP (e.g. lecture design and class activities) had been modified according to student feedback from course evaluations including subjective outcome evaluation, objective outcome evaluation, class observations, and focus groups [8]. The details of the nine lectures were presented as below.

- Lecture One: An overview of service leadership and attributes of effective service leaders

- Lecture Two: Introduction of the service leadership model and the core beliefs of service leadership; history and development of the service leadership model

- Lecture Three: Intrapersonal competencies and service leadership: intelligence quotient (IQ), emotional quotient (EQ), spiritual quotient (SQ), and adversity quotient (AQ)

- Lecture Four: Character strengths in Chinese philosophies; character strengths and service leadership

- Lecture Five: Factors leading to creation, development and maintenance of positive social relationship; interpersonal competencies (e.g. communication, conflict resolution skills) 
- Lecture Six: Caring dispositions and service leadership; becoming a caring service leader

- Lecture Seven: Developmental assets and service leadership; positive and healthy identity

- Lecture Eight: Leaders as mentors

- Lecture Nine: Self-leadership and service leadership; summary of service leadership curriculum and its core beliefs

After the nine lectures of the "Service Leadership" course, subjective outcome evaluation was carried out. This approach commonly used to provide useful information on the effectiveness of programs in youth research [16] is easily understood by beneficiaries and service providers [17]. Marsh and Roche [18] postulated that no single criterion is sufficient to evaluate the effectiveness of teaching due to the multidimensionality of teaching effectiveness. To comprehensively assess program effectiveness, Shek and his research team have developed a valid Subjective Outcome Evaluation Form for students in the Project P.A.T.H.S. (Positive Adolescent Training through Holistic Social Programmes) - a large-scale positive youth development program in Hong Kong [19-22]. After finding the Subjective Outcome Evaluation Form to be effective and useful, Shek and his colleagues modified this form and applied it to evaluation of several leadership courses $[12,23,24]$. The modified form has effectively measured a leadership course (i.e. "Tomorrow's Leaders") based on three dimensions: the course contents, the lecturers and benefits of the course concerning leadership development [23]. Because of its successful application, this evaluation form was employed to investigate the views of program participants on the "Service Leadership" subject in the GYLP. Three research questions revolved around the course effectiveness were proposed as follows:

- Research Question 1: What are the views of the students on the subject, including the subject matter and teaching-learning process, instructors, and benefits of the subject?

- Research Question 2: What are the relationships amongst the views toward the course contents, the lecturers, and course benefits?

Hypothesis 1a: It was hypothesized that the three domains of the program evaluation would be correlated.

Hypothesis $1 b$ : Based on previous findings, it was hypothesized that student perceptions of the course contents and the lecturers would positively predict their perceived benefits from the course.

- Research Question 3: Do the three domains of subjective outcome evaluation influence student overall satisfaction with the "Service Leadership" course in the GYLP?

Hypothesis 2a: It was predicted that the three domains would positively predict student willingness to suggest his/her friends to take this course.

Hypothesis $2 b$ : It was predicted that the three domains would positively predict student willingness to participate in similar courses again in the future.

Hypothesis 2c: It was predicted that the three domains would positively predict student overall satisfaction with this course.

- Research Question 4: Does the "Service Leadership" course in the GYLP show higher effectiveness than did the 2-credit "Service Leadership" course in PolyU? Hypothesis 3: As the subject was intensive, it was expected that the "Service Leadership" course in the GYLP would be more effective than the 2-credit "Service Leadership" course in PolyU indexed by the student satisfaction scores.

\section{Methods}

A total of 48 year-one undergraduate students were enrolled in the program, with 24 full-time students each from PolyU and PKU. Among these participants aged from 19 to 23 years old, 22.9\% were male $(n=11)$, and $77.1 \%$ were female $(n=37)$. Regarding ethnicity, there were $89.58 \%$ Chinese $(n=43), 6.25 \%$ Korean $(n=3)$, and $4.17 \%$ other ethnicities including one American and one Thai. Students came from different disciplines, such as engineering, philosophy, medicine, psychology, law, business, and journalism.

\section{Procedures}

Informed consent from students was obtained at the beginning of the course, and the Subjective Outcome Evaluation Forms were administered to students upon the completion of all lecture materials. Anonymity and confidentiality of the collected information were maintained in the study.

\section{Measures}

The Subjective Outcome Evaluation Form has been widely used in the evaluation of leadership courses at PolyU, with research showing that the scale had satisfactory reliability and validity [12]. In addition to personal information, the evaluation form consisted of seven parts. The first three parts (with a total of 38 items) attempted to measure student perceptions on the course content, lecturers, and perceived benefits ranging from 1 (strongly disagree) to 5 (strongly agree) as below:

- $\quad$ Perceptions of the course content (10 items; e.g. the activities were carefully arranged) including the objectives and design of 
the curriculum, classroom atmosphere, peer interaction, and student participation.

- $\quad$ Perceptions of the lecturers (10 items; e.g. the lecturers showed good professional attitudes) including lecturers' teaching skills, professional attitudes, involvement, and interaction with the students.

- Perceptions of the benefits of the course (18 items; e.g. it has enhanced my critical thinking) including improvement of different psychosocial competencies and overall personal development, and the achievement of the intended learning outcomes.

In part four and part five, students were asked to indicate how willing they were to recommend the course to their friends, as well as their willingness to participate in similar courses in the future (ranging from $1=$ definitely will not to $5=$ definitely will). Additionally, student overall satisfaction to the course was measured in the sixth part, where they were asked to indicate the extent of satisfaction from 1 (very dissatisfied) to 5 (very satisfied). In the last section, students were invited to complete four open-ended questions on the most important things they had learned from the course, what they appreciated most about the course, comments on the lecturers and suggestions for the improvements of the course.

\section{Data analytical plan}

Descriptive statistical analyses were used to examine the three domains of the program evaluation (i.e. student views on the course content, lecturers, and course benefits) and student overall satisfaction with the course. Correlation analyses were then conducted to examine the three domains. Regression analysis was performed to test whether the course content and lecturer quality could predict student perceived course benefits. Multiple regression analyses were used to examine whether the three domains could serve as predictors of student overall satisfaction, student willingness to recommend the course to their friends and to participate in similar courses in the future. Independent t-test was conducted to measure whether the GYLP "Service Leadership" subject was more effective than the 2-credit "Service Leadership" course at PolyU.

\section{Results}

A total of 47 students completed the Subjective Outcome Evaluation Forms in the last lecture of the course. Several observations should be highlighted.

With reference to the course content, most participants held positive perceptions (see Table 1). The percentage of respondents with positive responses (i.e. agreeing or strongly agreeing) to the items ranged from $83 \%$ to $95.7 \%$ across all items of the course content. For instance, $89.4 \%$ of students appreciated the classroom atmosphere, and $89.1 \%$ of students appreciated the well-arranged activities. Overall, $93.6 \%$ of students had a very positive evaluation on the course, and $91.5 \%$ of students liked this course very much.

With regard to the lecturers, all students (100\%) appreciated the performance of lecturers (see Table 2). Specifically, 97.9\% of students felt that the lecturers had good mastery of the course materials, arrived well prepared for the lessons, cared for the students, and encouraged student participation in the class activities.

With respect to the perceived benefits of the course, $85.1 \%$ of students believed that it had promoted their overall development (see Table 3). On the development of intrapersonal competencies, perceived benefits included improvements in positive attitudes to the future (91.5\%), enhancement of comprehensive character strengths $(89.4 \%)$, and strengthening of self-leadership ability $(89.3 \%)$. Improvements in interpersonal competencies were also noted, such as the enhancement in social competence (93.6\%) and cultivation of love and care for others (93.6\%). More importantly, the course enabled students to better understand the importance of situational task competencies, character strengths, and caring dispositions in

Table 1: Student perceptions of the course content.

\begin{tabular}{rrr}
\hline Mean (SD) & n & \% (valid) \\
\hline $4.28(0.88)$ & 41 & 87.2 \\
$4.11(0.81)$ & 39 & 83.0 \\
$4.26(0.80)$ & 41 & 89.1 \\
$4.51(0.69)$ & 42 & 89.4 \\
$4.66(0.56)$ & 45 & 95.7 \\
$4.43(0.74)$ & 42 & 89.4 \\
$4.34(0.76)$ & 41 & 87.2 \\
$4.21(0.69)$ & 40 & 85.1 \\
$4.28(0.71)$ & 44 & 93.6 \\
$4.23(0.73)$ & 43 & 91.5 \\
\hline
\end{tabular}

1. The objectives of the curriculum are very clear.

2. The content design of the curriculum is very good.

3. The activities were carefully arranged.

4. The classroom atmosphere was very pleasant.

5. There was much peer interaction amongst the students.

6. I participated in the class activities actively (including discussions, sharing, games, etc.).

7. I was encouraged to do my best.

8. The learning experience enhanced my interests towards the course. 
Table 2: Student perceptions of the lecturers.

Lecturer attributes
Respondents with positive responses ( 4 and 5)

\begin{tabular}{rrr}
\hline Mean (SD) & n & \% (valid) \\
\hline $4.49(0.55)$ & 46 & 97.9 \\
$4.66(0.52)$ & 46 & 97.9 \\
$4.34(0.67)$ & 42 & 89.4 \\
$4.60(0.54)$ & 46 & 97.9 \\
$4.66(0.56)$ & 45 & 95.7 \\
$4.68(0.52)$ & 46 & 97.9 \\
$4.64(0.53)$ & 46 & 97.9 \\
$4.62(0.57)$ & 45 & 95.7 \\
$4.53(0.62)$ & 44 & 93.6 \\
$4.55(0.50)$ & 47 & 100.0 \\
\hline
\end{tabular}

00.0

1. The lecturer(s) had a good mastery of the course.

2. The lecturer(s) was (were) well prepared for the lessons.

3. The teaching skills of the lecturer(s) were good.

4. The lecturer(s) showed good professional attitudes.

5. The lecturer(s) was (were) very involved.

6. The lecturer(s) encouraged students to participate in the activities.

7. The lecturer(s) cared for the students.

8. The lecturer(s) was (were) ready to offer help to students when needed.

9. The lecturer(s) had much interaction with the students.

10. Overall speaking, I have a very positive evaluation on the lecturer(s).

All items are on a 5-point Likert scale with 1=strongly disagree, 2=disagree, 3=neutral, 4=agree, 5=strongly agree.

Table 3: Student perceptions of the perceived course benefits.

Perceived course benefits

Respondents with positive responses (4 and 5)

2. It has improved my ability in expressing and handling my emotions.

3. It has enhanced my critical thinking.

4. It has increased my competence in making sensible and wise choices.

5. It has helped me make ethical decisions.

6. It has strengthened my resilience in adverse conditions.

7. It has strengthened my self-confidence.

8. It has helped me face the future with a positive attitude.

9. It has enhanced my love for life.

10. It has helped me explore the meaning of life.

11. It has enhanced my ability of self-leadership.

12. It has helped me cultivate compassion and care for others.

13. It has helped me enhance my character strengths comprehensively.

14. It has enabled me to understand the importance of situational task competencies, character strength and caring disposition in successful leadership.

15. It has promoted my sense of responsibility in serving the society.

16. It has promoted my overall development.

17. The theories, research and concepts covered in the course have enabled me to understand the characteristics of successful service leaders.

18. The theories, research and concepts covered in the course have helped me synthesize the characteristics of successful service leaders.

\begin{tabular}{llr} 
Mean (SD) & n & \% (valid) \\
\hline $4.26(0.64)$ & 44 & 93.6 \\
$4.06(0.70)$ & 39 & 83.0 \\
$3.91(0.80)$ & 35 & 74.5 \\
$3.83(0.87)$ & 32 & 68.1 \\
$4.09(0.93)$ & 37 & 78.7 \\
$3.83(0.94)$ & 33 & 70.2 \\
$4.17(0.73)$ & 40 & 85.1 \\
$4.38(0.71)$ & 43 & 91.5 \\
$4.09(0.78)$ & 41 & 87.2 \\
$4.04(0.83)$ & 36 & 76.6 \\
$4.19(0.74)$ & 42 & 89.3 \\
$4.21(0.78)$ & 44 & 93.6 \\
$4.17(0.60)$ & 42 & 89.4 \\
$4.47(0.58)$ & 45 & 95.7 \\
& & 85.1 \\
$4.09(0.83)$ & 40 & 85.1 \\
$4.15(0.86)$ & 40 & 91.5 \\
$4.38(0.71)$ & 43 & 87.2 \\
$4.40(0.77)$ & 41 &
\end{tabular}

All items are on a 5-point Likert scale with $1=$ unhelpful, 2 =not very helpful, $3=$ slightly helpful, $4=$ helpful, $5=$ very helpful.

successful leadership (95.7\%) and to understand the characteristics of successful service leaders (91.5\%).

In addition to the three domains, results (see Table 4) showed that $89.1 \%$ of the participants were satisfied or highly satisfied with the course. Moreover, a majority of students "would" or "definitely would" recommend the course to their friends (85.1\%) and participate in similar courses in the future $(68.1 \%)$.

The high reliabilities of the scales used in this evaluation are presented in Table 5. As predicted, curriculum content, lecturer quality and perceived course benefits were significantly and positively correlated with each other $(r s=0.60-0.73, p<0.001)$. Using regression analysis, we found that course content was a significant predictor of perceived course benefits $(\beta=0.59, \mathrm{p}<0.001)$, while lecturer attributes did not influence the perceived benefits $(\beta=0.20, \mathrm{p}>0.05)$.

Besides, Table 6 revealed that course content was a significant predictor for whether students would take similar courses in the future $(\beta=0.54, \mathrm{p}<0.01)$, and 
Table 4: Student overall satisfaction with the course.

\begin{tabular}{|c|c|c|c|c|c|c|c|}
\hline & \multirow[b]{2}{*}{1} & \multirow[b]{2}{*}{2} & \multirow[b]{2}{*}{3} & \multicolumn{2}{|c|}{ Responses } & \multirow{2}{*}{\multicolumn{2}{|c|}{$\begin{array}{r}\text { Respondents with } \\
\text { positive responses } \\
(4 \text { and } 5)\end{array}$}} \\
\hline & & & & 4 & 5 & & \\
\hline & $\mathbf{n}$ & $\mathbf{n}$ & $\mathbf{n}$ & $\mathbf{n}$ & $\mathbf{n}$ & $\mathbf{n}$ & $\%$ (valid) \\
\hline 1. Will you suggest your friends to take this course?a & 0 & 2 & 5 & 29 & 11 & 40 & 85.1 \\
\hline 2. Will you participate in similar courses in the future? & 2 & 2 & 11 & 22 & 10 & 32 & 68.1 \\
\hline 3. On the whole, are you satisfied with this course? ${ }^{b}$ & 0 & 1 & 4 & 30 & 11 & 41 & 89.1 \\
\hline
\end{tabular}

a1=Definitely will not, $2=$ will not, $3=$ not sure, $4=$ will, $5=$ definitely will; ${ }^{\mathrm{b}} 1=$ very dissatisfied, $2=$ moderately dissatisfied, $3=$ neutral, $4=$ satisfied, $5=$ very satisfied.

Table 5: Means, standard deviations, reliabilities and correlations of the variables.

\begin{tabular}{|c|c|c|c|c|c|c|c|c|c|c|}
\hline & Mean & SD & $\alpha$ & 1 & 2 & 3 & 4 & 5 & 6 & 7 \\
\hline 1. Course content & 4.33 & 0.51 & 0.88 & 1 & & & & & & \\
\hline 2. Lecturer attributes & 4.58 & 0.42 & 0.91 & $0.67^{\mathrm{a}}$ & 1 & & & & & \\
\hline 3. Perceived course benefits & 4.15 & 0.57 & 0.95 & $0.73^{a}$ & $0.60^{\mathrm{a}}$ & 1 & & & & \\
\hline 4. Overall effectiveness & 4.31 & 0.46 & 0.96 & $0.88^{\mathrm{a}}$ & $0.79^{a}$ & $0.94^{\mathrm{a}}$ & 1 & & & \\
\hline 5. Willingness to suggest friends to take the course & 4.04 & 0.72 & - & $0.58^{\mathrm{a}}$ & $0.33^{b}$ & $0.63^{\mathrm{a}}$ & $0.62^{\mathrm{a}}$ & 1 & & \\
\hline 6. Willingness to participate in similar courses in the future & 3.77 & 0.98 & - & $0.56^{\mathrm{a}}$ & 0.26 & $0.49^{\mathrm{a}}$ & $0.52^{\mathrm{a}}$ & $0.78^{\mathrm{a}}$ & 1 & \\
\hline 7. Overall satisfaction with the course & 4.11 & 0.64 & - & $0.62^{\mathrm{a}}$ & $0.53^{\mathrm{a}}$ & $0.57^{\mathrm{a}}$ & $0.64^{\mathrm{a}}$ & $0.75^{\mathrm{a}}$ & $0.64^{\mathrm{a}}$ & 1 \\
\hline
\end{tabular}

${ }^{\mathrm{a}} \mathrm{p}<0.001,{ }^{\mathrm{b}} \mathrm{p}<0.05$

Table 6: Multiple regression analyses predicting student willingness to recommend the course to friends, take similar courses in the future and overall satisfaction to the course.

\begin{tabular}{|c|c|c|c|c|c|}
\hline & & & Predictors & \multicolumn{2}{|r|}{ Model } \\
\hline & Course content & Lecturers & Course benefits & & \\
\hline & $\beta$ & $\beta$ & $\beta$ & $\mathbf{R}$ & $\mathbf{R}^{2}$ \\
\hline Willingness to suggest friends to take course & 0.35 & -0.20 & $0.49^{a}$ & 0.67 & 0.45 \\
\hline Willingness to participate in similar courses in the future & $0.54^{\mathrm{a}}$ & -0.25 & 0.25 & 0.60 & 0.36 \\
\hline Overall satisfaction with course & 0.35 & 0.16 & 0.21 & 0.65 & 0.42 \\
\hline
\end{tabular}

${ }^{\mathrm{a}} \mathrm{p}<0.01$

perceived course benefits accounted for whether students would recommend the course to their friends $(\beta=0.49$, $\mathrm{p}<0.01)$. None of the course content, lecturer quality, and perceived course benefits could independently influence student overall satisfaction with the course ( $p s>0.05)$.

Additionally, four open-ended questions were asked in terms of the most important thing learned from the course, the greatest appreciation on the course, comments on the lecturers and suggestions to the course. Some typical feedback is listed below:

- The most important thing learned: "definition of IQ, EQ, AQ and SQ"; "caring for others"; "love and interpersonal relationship"; and "self-leadership”.

- The greatest appreciation: "amazing activities"; "we can share our thoughts and being inspired by others"; and "the teachers are really kind, passionate, patient and outstanding".

- Comments on the lecturers: "active"; "good and professional"; and "very nice and helpful".

- Suggestions to the course: "shorten the lecture time"; "organize more discussion and debate on social issues"; and "provide more practical skills and examples".

Finally, the "Service Leadership" course in the GYLP showed higher effectiveness than did the 2-credit general education course in PolyU [11]. We found GYLP students have higher perceptions on the course content $(4.33>3.86$, $t=-4.369, \quad \mathrm{p}<0.001)$, lecturer attributes, $(4.58>4.25$, $t=-3.782, \quad \mathrm{p}<0.001)$ and perceived course benefits 
(4.15 $>3.82, t=-2.935, \mathrm{p}<0.01)$. Compared to students in the "Service Leadership" course at PolyU, a higher portion of students in the GYLP had the willingness to recommend the course to their friends $(4.04>3.72, t=-1.920, \mathrm{p}<0.10)$ and participate in similar courses in the future $(3.77>3.38$, $t=-1.972, \mathrm{p}<0.10$ ), and had a higher level of overall satisfaction with the course (4.11>3.82, $t=-2.171, \mathrm{p}<0.05)$.

\section{Discussion}

With the fast development of the service economy, the growing need to promote youth leadership calls for the emergence of service leadership education in Chinese university students. To promote the holistic development of a young generation, the GYLP was designed for undergraduates in Hong Kong and Mainland China aiming to promote the intrapersonal and interpersonal relationship of young students and to strengthen youth leadership. The present study was conducted to examine the post-course perceptions on the service leadership course offered as a part of the GYLP for students from PolyU or PKU. The findings of this study strongly supported the effectiveness and value of the service leadership course in the GYLP. A majority of students were very satisfied with the course in the GYLP with positive perceptions of the course content, lecturers, and course benefits that were significantly related to each other. Also, most students expressed their willingness to recommend this course to others and to attend similar courses in the future. These encouraging findings further demonstrated the effectiveness of service leadership education on positive youth development and supported the positive results of subjective outcome evaluation in previous service leadership courses [12].

Diverging slightly from a previous study regarding the subjective outcome evaluation of leadership education [23], we found that only course content could be regarded as a predictor of perceived course benefits while there was no impact of lecturer attributes on student perceived course benefits. One possibility explains this difference: the course duration of service leadership in the GYLP was only 4.5 days, and such a short period may hinder the connection between lecturers and students, thereby weakening the influence of lecturers in the course benefits. The other possibility is that small sample size $(n=47)$ may have inadequate statistical power. Finally, the high correlation between program and instructor may create statistical artifact.

Controlling for the other two domains, perceived course benefits was found to be the sole predictor of student willingness to recommend friends to take the course. This suggests that, if students can get some benefits from the course (e.g. improvement of the personal competence, enhancement of self-leadership ability, and promotion of overall development), they are more likely to suggest others to take the course. Regarding whether students will participate in similar courses in the future, course content rather than lecturer attributes and course benefits became the significant determinant. This implies that when students decided to register in similar courses, the contents of the courses they participated previously was very important to their decision. Interestingly, we found course contents, lecturer qualities, and perceived course benefits did not independently influence student overall satisfaction with the course. This may be because that the three domains were inter-correlated with each other, and they had the same important roles for student overall satisfaction. In other words, student overall satisfaction was decided by the course contents, lecturer attributes, and the perceived course benefits together.

In addition to the closed-ended questions, the openended questions also supported the effectiveness of the "Service Leadership" course in GYLP in terms of the three domains. Although there is still room for further refinement (e.g. more discussion is expected to be organized), most students had very positive evaluations on the course contents (e.g. activities) and lecturers (e.g. very helpful). The high quality of course contents and lecturers resulted in a high proportion of students enjoying the course and claiming improvement in their leadership qualities (e.g. self-leadership and interpersonal skills).

Finally, it was found that subjective outcomes in "Service Leadership" course under the GYLP were better than that in the course at PolyU. Specifically, students in the GYLP showed a higher level of overall satisfaction with the course with significantly better perceptions on the course content, lecturer attributes, and perceived course benefits. Three reasons may contribute to this encouraging finding. First, the intensive short-term course strengthens the learning outcomes of students compared to traditional fixed course design $[14,15]$. Second, the modified course in the GYLP has drawn experiences (e.g. course arrangement and teaching approaches) from the pioneer attempt at PolyU during semester 2 in academic year 2012-13. Third, before teaching "Service Leadership" course in the GYLP, some orientated learning and warm-up activities (e.g. dialogue with local leaders, visits to local communities, and group projects) were provided to the students in their home institutions (i.e. PolyU and PKU, respectively). It led students to have a general idea about service 
leadership, including its objectives, beliefs, missions, and values. These positive changes demonstrated that the course content, lecturer teaching skills, and perceived course benefits have been improved in "Service Leadership" course under the GYLP, although the effectiveness of the first "Service Leadership" course provided in PolyU had already been found to be satisfactory.

Although subjective outcome evaluation is limited in the Chinese context and this study enriches the literature on subjective outcome evaluation of program, several limitations should be noted. First, the small sample size of this study hinders the generalizability of the research findings to some extent, and the study should be replicated with more program participants. Second, the views of other stakeholders (e.g. course lecturers and program administrators) should be investigated to understand the course effectiveness from multiple perspectives. Third, as the current study is a cross-sectional study, longitudinal studies would allow researchers to explore the long-term impacts of the program. Despite these limitations, the present study as a pioneer study provides very convincing and beneficial evidence to support the effectiveness of "Service Leadership" course and promote the development of service leadership education in the Chinese society.

\section{References}

1. Shek DT, Chung PY, Leung H. Manufacturing economy versus service economy: implications for service leadership. Int J Disabil Hum Dev 2015;14:205-15.

2. Hong Kong: The facts, 2013. Available at: http://www.gov.hk/en/ about/abouthk/factsheets/docs/trade\&industry.pdf.

3. National data. National Bureau of Statistics of the People's Republic of China, 2014. Available at: http://data.stats.gov.cn/ workspace $/$ index $? a=q \&$ type $=$ global $\& d b c o d e=h g n d \& m=h g n d \& d$ imension $=z b \&$ code $=A 020102 \&$ region $=000000 \&$ time $=2013$.

4. KPMG Huazhen (Special General Partnership). China's banking sector: hot topics and performance of listed banks in 2013, 2014. Available at: http://www.kpmg.com/CN/en/IssuesAndInsights/ ArticlesPublications/Documents/Hot-topics-and-performance-oflisted-banks-in-2013-201404.pdf.

5. China overtakes Japan as world's second-biggest economy, 2011. Available at:http://www.bbc.co.uk/news/business-12427321.

6. Chung P. Hong Kong institute of service leadership and management curriculum framework. Unpublished document, Hong Kong: Hong Kong institute of leadership and management, 2011.

7. Chung P. Service reborn. New York: Lexingford Publishing, 2012.
8. Shek DT, Sun RC, Yu L, Ma CM, Siu AM, Lin L, et al. Service leadership education and research at The Hong Kong Polytechnic University: an overview. Paper presented at: The International Conference on Service Leadership Education for University Students: Experience in Hong Kong; 2014 May 14-15; Hong Kong SAR, China.

9. Chung P. HKI-SLAM's core beliefs (CB 1-7) about service leadership and management, 2011. Available at: http://server.gopublic.com.hk:3993/slam/index. php? $r=$ article $\&$ catid=2\&aid=22.

10. Hong Kong Institute of Service Leadership and Management (HKI-SLAM). SLAM Education, 2013. Available at: http://server. gopublic.com.hk:3993/slam/index.php?r=article\&catid=2\& aid $=20$.

11. Shek DT, Lin L, Leung H, Law M, Li X. Evaluation of service leadership programs using multiple evaluation methods. Paper presented at: The International Conference on Service Leadership Education for University Students: Experience in Hong Kong; 2014 May 14-15; Hong Kong SAR, China.

12. Shek DT, Lin L, Liu TT. Service leadership education for university students in Hong Kong: subjective outcome evaluation. Int J Disabil Hum Dev. 2014;13:513-21.

13. Shek DT, Yu L, Ma C, Sun RC, Liu TT. Development of a creditbearing service leadership subject for university students in Hong Kong. Int J Adolesc Med Health 2013;25:353-61.

14. Kucsera JV, Zimmaro DM. Comparing the effectiveness of intensive and traditional courses. Coll Teach 2010;58:62-8.

15. Scott PA. Attributes of high-quality intensive courses. New Dir Adult Contin Educ 2003;97:29-38.

16. Shek DT. Is subjective outcome evaluation related to objective outcome evaluation? Insights from a longitudinal study in Hong Kong. J Pediatr Adolesc Gynecol 2014;27:S50-6.

17. McMurtry SL, Hudson WW. The Client Satisfaction Inventory: results of an initial validation study. Res Social Work Pract 2000;10:644-63.

18. Marsh HW, Roche LA. Making students' evaluations of teaching effectiveness effective: the critical issues of validity, bias, and utility. Am Psychol 1997;52:1187-97.

19. Shek DT, Siu MH, Lui J, Lung WM. P.A.T.H.S. to adulthood: a Jockey Club Youth Enhancement Scheme (evaluation manual). Hong Kong: Social Welfare Practice and Research Centre, The Chinese University of Hong Kong, 2006.

20. Shek DT, Ma HK. Subjective outcome evaluation of the Project PATHS: findings based on the perspective of the program participants. Sci World J 2007;7:47-55.

21. Shek DT, Ma C, Tang CY. Predictors of subjective outcome evaluation findings in a positive youth development program in Hong Kong. Int J Disabil Hum Dev 2011;10:249-55.

22. Shek DT, Ng CS. Subjective outcome evaluation of the Project P.A.T.H.S. (Secondary 2 Program): views of the program participants. Sci World J 2009;9:1012-22.

23. Shek DT, Sun RC. Post-course subjective outcome evaluation of a course promoting leadership and intrapersonal development in university students in Hong Kong. Int J Disabil Hum Dev 2013;12:193-201.

24. Shek DT, Sun RC. Promoting leadership and intrapersonal competence in university students: what can we learn from Hong Kong? Int J Disabil Hum Dev 2012;11:221-8. 